\title{
Waveform inversion and analysis of an unusual earthquake swarm in the Boshan mining area, Shandong Province, China
}

\author{
Jian-Chang Zheng $\cdot$ Jin-Hua Zhao $\cdot$ Chang-Peng Xu $\cdot$ Peng Wang
}

Received: 8 October 2015/Accepted: 18 January 2016/Published online: 23 February 2016

(C) The Author(s) 2016. This article is published with open access at Springerlink.com

\begin{abstract}
Moment tensor solutions were retrieved for the earthquake swarm that occurred during November and December 2010 in the Boshan mining area, Shandong Province, China. The results showed that the double-couple components in the source mechanisms were higher at the beginning of the swarm and consisted mainly of shear faulting controlled by tectonic stress. The subsequent events had significant non-double-couple components, indicating tensile faulting. The double-couple components predominately presented as normal faulting and the $\mathrm{P}$ axes were orientated almost vertically. The slip vectors of the swarm events were relatively stable. With reference to the tectonic features near the epicenter, we concluded that the swarm was a result of subordinate fault motion related to the Wangmu Mountain fault and that high-pressure pore fluids played a crucial role in the activity of the earthquake swarm.
\end{abstract}

Keywords Moment tensor - Tensile crack - Mechanism . Boshan earthquake swarm - Pore pressure

\section{Introduction}

In 2010, a series of earthquake occurred near Boshan, a mining area city in the past in Shandong Province, China. The earthquake sequence continued over 1 month, from November 24, 2010 to December 27, 2010 and were measured by the Shandong seismic network. The tremors from these earthquakes propagated widely through these

J.-C. Zheng $(\bowtie) \cdot$ J.-H. Zhao $\cdot$ C.-P. Xu $\cdot$ P. Wang

Earthquake Administration of Shandong Province, Jinan 250014, China

e-mail: zjcmail@yeah.net mining areas and affected almost all the villages in Boshan, with consequent social impacts. There were six earthquakes of $M_{\mathrm{L}} \geq 2.0$ and the maximum event of $M_{\mathrm{L}} 3.4$ occurred on December 20, 2010. This event had the highest magnitude of all the earthquakes that have occurred in the mining areas of Shandong Province in recent years.

The term "mine earthquake" is used here to refer to all earthquakes occurring in mining areas, whether they were caused by rock bursts, mine collapses, or tectonics. Mine earthquakes can be divided into three types: (1) earthquakes in which a rupture occurs in the surrounding rock mass of the mining areas-these are caused by the adjustment of stress in the Earth's crust and result in slippage along a few minor faults; (2) shocks caused by mine collapse, roof falls, or rock bursts; and (3) shocks caused by the detonation of gas or powdered coal in mine tunnels (Zhang et al. 1993). The source of the earthquake is obviously different in each of these three categories. The source type can be indicated by the moment tensor. For earthquakes caused by tectonic activity resulting from stress adjustment in mining areas, the source mechanism follows the double-couple (DC) shear dislocation model and is close to that of natural earthquakes. The source of earthquakes caused by mine collapse, roof falls, or rock bursts is primarily uniaxial compression, and there is a large compensated linear vector dipole (CLVD) component in the moment tensor solutions and a characteristic implosion mechanism resulting from the sudden closure of goafs. For mine earthquakes resulting from the detonation of gas or powdered coal, the explosive source (i.e., the isotropic volume component) plays a large part in the source mechanism. Some studies have shown that many mine earthquakes have non-DC mechanisms and may contain a large volume or linear component under some 
circumstances (Gibowicz and Kijko 1998; McGarr 1992a, b; Feignier and Young 1992; Phillips et al. 1999; Fletcher and McGarr 2005; Stec 2007; Julià et al. 2009). There have been a number of studies in China in recent years of the source mechanisms of mining-induced earthquakes ( $\mathrm{Li}$ et al. 2005; He et al. 2007; Chen et al. 2009), although there has been little specific research into the moment tensor of mine earthquakes.

Non-tectonic earthquakes and natural earthquakes are technically distinguishable as they differ in many aspects, such as the first motion of the seismic waves, the ground motion frequency, and the rate of attenuation. Many researchers have conducted in-depth research into the differences between non-tectonic and natural earthquakes using seismic waveforms. For example, Lin et al. (1990) compared the seismic phase characteristics of collapse earthquakes and tectonic earthquakes and suggested that collapse earthquakes have a different wave propagation velocity, attenuation, and amplitude. Gibowicz (1995) studied the relationship between the seismic moment of mining-induced events and the $\mathrm{P}$ and $\mathrm{S}$ wave corner frequencies in various regions using statistical comparisons. Oye et al. (2005) studied seismic source parameters such as the coda attenuation and apparent stress of a mine earthquake swarm in Finland using the spectral integral and multiple empirical Green's functions. He et al. (2006) and Liu et al. (2005) solved the recognition factors for mine and tectonic earthquakes based on wavelet packet decomposition of the waveform. Shen et al. (2006) studied the rupture and nucleation processes of mine earthquakes based on micro-tremor records and micro-seismic waveforms in mining areas. Zhang et al. (2009) compared and analyzed the time-frequency characteristics of the spectra of mine and tectonic earthquakes in the Three Gorges area of China.

During emergency work after this swarm of earthquakes in 2010, we noticed that these particular mine earthquake events differed from ordinary mine earthquakes and that there was a need for further analysis. Moment tensor analysis is a powerful tool for source mechanism studies. Therefore, we analyzed and inverted all the digital waveform recordings of these mine earthquake swarm events to determine the source moment tensor solutions.

\section{Data and information}

2.1 Distribution of the earthquake swarm and seismic stations

A total of six events with $M_{\mathrm{L}} \geq 2.0$ were recorded in the Boshan earthquake swarm. In addition, one event with $M_{\mathrm{L}}$ 2.7 occurred near the epicenter of the Boshan swarm on September 12, 2010 and, while the swarm was active, one event with $M_{\mathrm{L}} 2.7$ occurred $16 \mathrm{~km}$ to the south of the epicenter on November 25, 2010. As these two events were closely related to the Boshan swarm both tectonically and in time, they were also included in our study. All the broadband digital seismic stations within $150 \mathrm{~km}$ of the epicenters of the largest magnitude events in the swarm recorded relatively clear waveform signals. Figure 1 shows

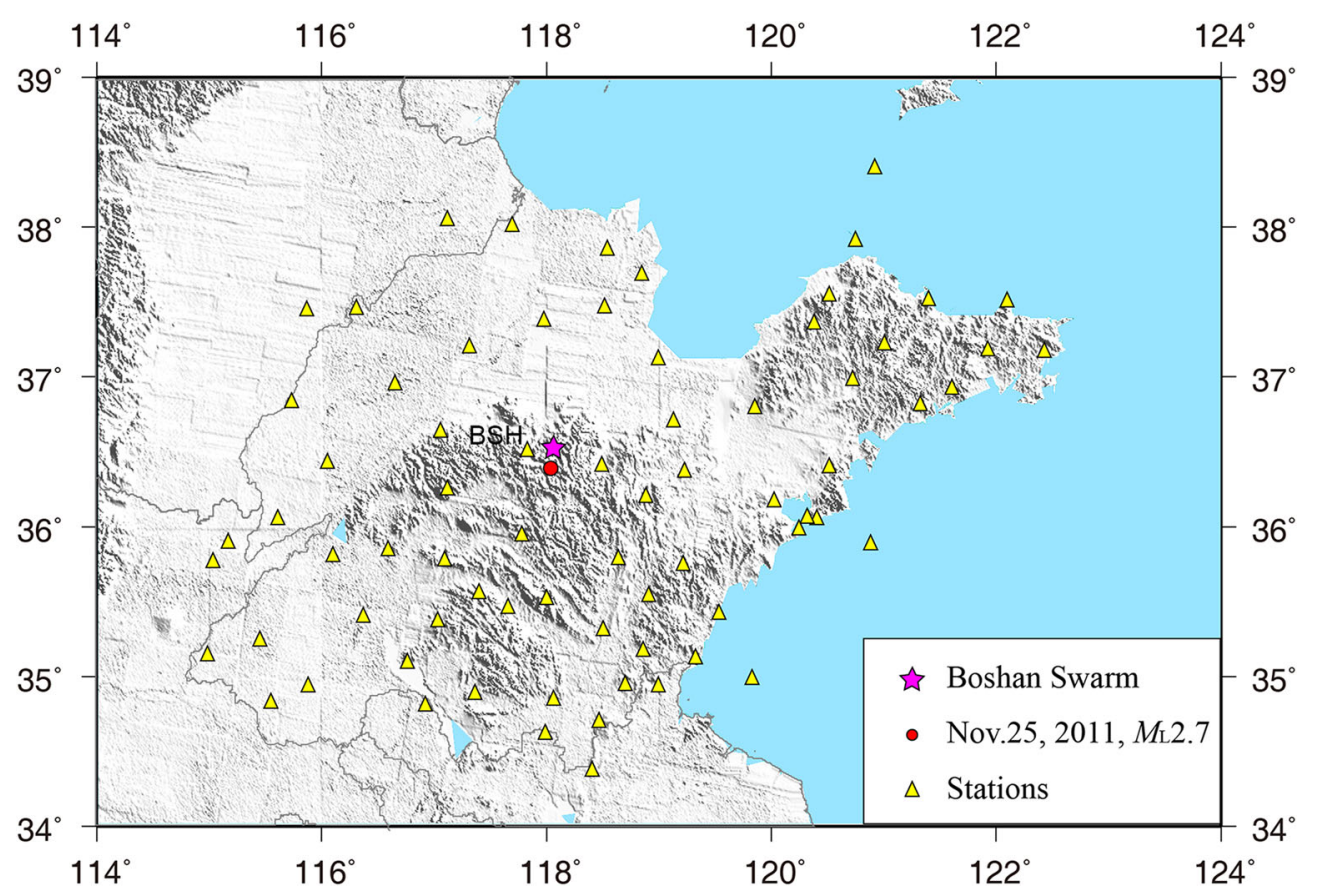

Fig. 1 Distribution of the Boshan swarm and the seismic stations in Shandong Province, China 
the distribution of the epicenters of the mine earthquake events and the broadband seismic stations in Shandong area.

After several mine earthquakes in late November 2010, the Earthquake Networks Center of Shandong Province and the Earthquake Administration of Zibo City set up four mobile seismic stations in the vicinity of the epicenter. These four stations plus the BSH station, which is $<10 \mathrm{~km}$ from the epicenter, formed a temporary seismic network of five stations and recorded several mine earthquake events. Figure 2 shows the relocated epicenters of the Boshan swarm, and the temporary stations at the Boshan area.

The data from the temporary stations show that the S-P value is $>0.5 \mathrm{~s}$ at the closest station L02; the relocated results show that the focal depths of all these events ranged from 4 to $5 \mathrm{~km}$. The depths of mine earthquake events such as rock bursts and collapses caused by industrial mining activities are usually of the order of hundreds of meters, although they may exceed $2 \mathrm{~km}$ in a few deep mine areas [e.g., deep gold mines in South Africa (McGarr et al. 2009)]. However, according to data from the Zibo Mining Group Co. Ltd (Jiao et al. 1990), the Zibo coalfield contains Carboniferous-Permian coal measures with $>20$ layers of coal, 12 of which are minable in part or in whole; the main coal-bearing strata are $250 \mathrm{~m}$ thick and the mining depths are normally in the range of 200-300 m, with a maximum of $<400 \mathrm{~m}$. Therefore, the cause of this set of events may not be due purely to mining operations, such as rock bursts. As the epicenter of this earthquake swarm lies in the coal mining area, some researchers have called it a "mine earthquake" swarm; however, we refer to it as an "earthquake swarm" in this study.

Figure 3 shows the velocity model used in our study, which is derived from geophysical exploration in Shandong area (Jiang et al. 2000). The epicenter locations obtained through relocation was used in the inversion of the source

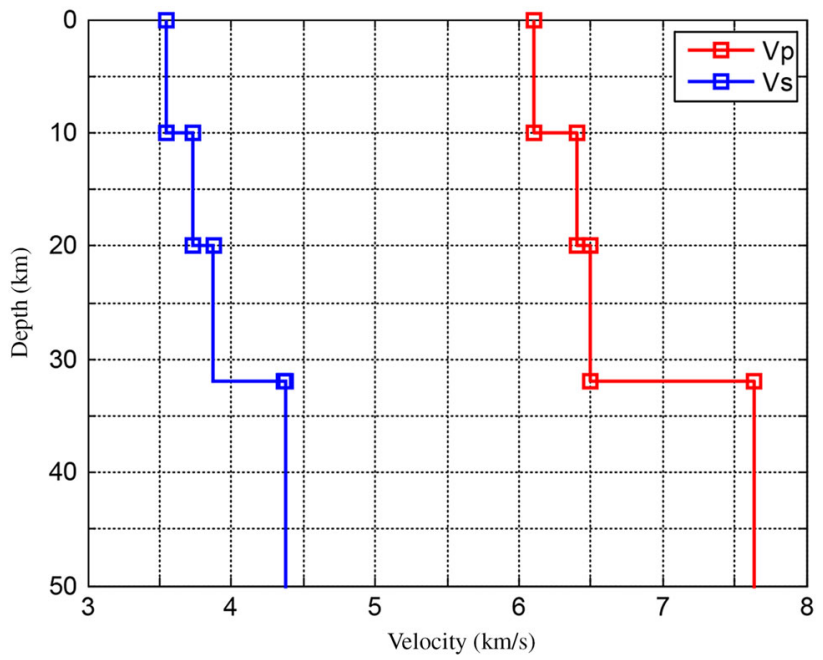

Fig. 3 Velocity model used in our study

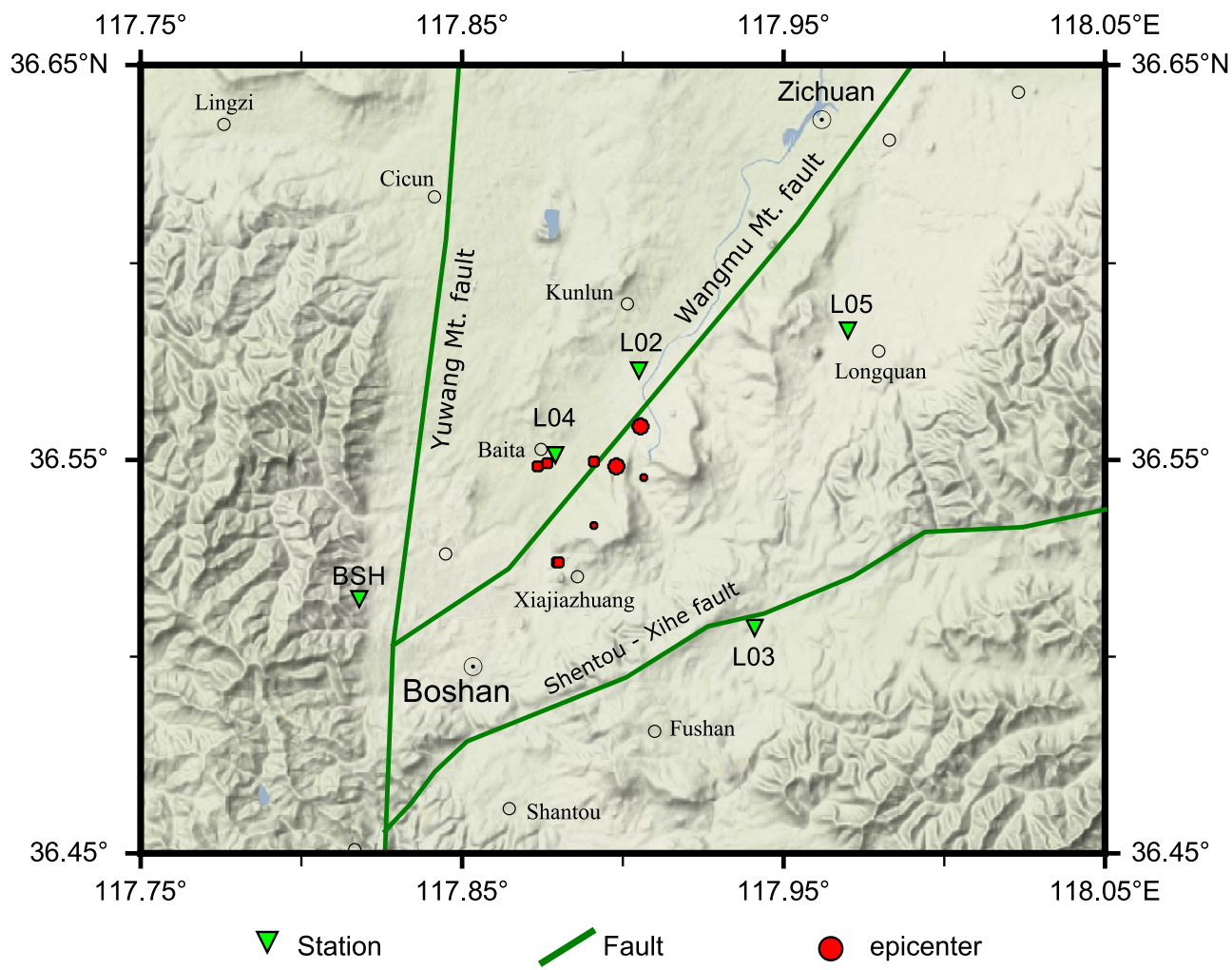

Fig. 2 Distribution of relocated events (red points) and stations in the temporary seismic network (green triangles) 
moment tensor. The search was conducted in the depth direction with a starting depth of $1 \mathrm{~km}$ and a step length of $1 \mathrm{~km}$. In total, there were 23 search depths to a maximum of $23 \mathrm{~km}$.

\subsection{Waveform time-frequency analysis of Boshan swarm}

Zhang et al. (2009) have shown that there are a few clear differences between the waveform time-frequency analysis results for mine and tectonic earthquakes. First, the main frequencies of the waves from tectonic earthquakes are higher than those of mine earthquakes. Second, the frequency components of waves from tectonic earthquakes are richer than those of mine earthquakes and their energy density spectrum is spread over a wider range of frequencies-the bandwidth of tectonic earthquakes is four times as wide as that of mine earthquakes. Third, the peak energy intensity of mine earthquakes over the entire wave train appears much earlier than that of tectonic earthquakes, although the attenuation in energy is more rapid. The timefrequency spectrogram of the Boshan earthquake swarm events shows that the events have distinctive features. The events share some characteristics with general mine earthquake events, such as a low main frequency and rapid attenuation. However, the energy density spectrum of the events is widely spread along the frequency axis and the dominant frequency of the $\mathrm{S}$ waves extends from about 7 to $17 \mathrm{~Hz}$ (Fig. 4), indicating the rich frequency components of the event.

\section{Theory and methods}

\subsection{Moment tensor decomposition of mine earthquakes}

In mathematics, the moment tensor describes the effectiveness of any type of source and can be simply divided into three parts corresponding to different types of sources: an isotropic (ISO) component, a CLVD subcomponent, and a DC component. The DC tensor describes the shear slip in isotropic media along fault planes and the ISO component corresponds to explosive or implosion sources. The ISO and CLVD components are referred to as the non-DC components and are attributable to the opening or closing of faults.

Many studies on the source moment tensor of mine earthquakes have shown that, as a result of the volume change caused by the closure of goafs, the source mechanisms of mine earthquakes (also referred to as "shock bump" or "rock burst") can be decomposed into a combination of two modes: shear slip accompanied by a certain amount of a co-seismic implosion component. McGarr
(1994) studied the mechanisms of mine earthquakes and found that the combination of a shear faulting model plus an implosion component could explain the waveforms of similar events observed in deep gold mines in South Africa (McGarr 1992a, b). Increasing numbers of studies are showing that many shallow, naturally occurring mine collapse events have an implosion mechanism as the seismic source (Gibowicz and Kijko 1998; Miller et al. 1998).

Yang et al. (1998) studied explosion-induced mine collapse. The results of source moment tensor inversion showed that the source mechanism of collapse can be expressed by horizontal opening and an implosion. Analysis showed that the unique source characteristics inducing collapse result from the fact that, unlike synchronous collapse, ordinary collapse is initially caused by extension fractures.

Unlike tectonic earthquakes caused by ordinary shear faulting, the fault slip vectors of mine earthquake events are not limited to the fault planes and may deviate from them. For normal seismic sources, the moment tensor can be expressed as a function of a slip vector. Aki and Richards (1980) devised a formula for the point source moment tensor of faults in isotropic media:

$M_{k l}=\lambda\left[u_{i}\right] n_{i} \delta_{k l}+\mu\left(\left[u_{k}\right] n_{l}+\left[u_{l}\right] n_{k}\right)$,

where $\lambda$ and $\mu$ are the Lamé constants of the faults, $\delta_{k l}$ is the Kronecker symbol, $[\boldsymbol{u}]$ is the slip vector, and $\boldsymbol{n}$ is the normal fault plane. If

$\boldsymbol{n}=(0,0,1)^{\mathrm{T}},[\boldsymbol{u}]=\boldsymbol{u}(\cos \alpha, 0, \sin \alpha)^{\mathrm{T}}$

then the moment tensor may be in the following form:

$\boldsymbol{M}=u\left[\begin{array}{ccc}\lambda \sin \alpha & 0 & \mu \cos \alpha \\ 0 & \lambda \sin \alpha & 0 \\ \mu \cos \alpha & 0 & (\lambda+2 \mu) \sin \alpha\end{array}\right]$,

where $\alpha[-\pi / 2, \pi / 2]$ is the included angle between the slip vector and the fault plane. When $\alpha>0$, the source is an extension fracture; when $\alpha<0$, it is a compression fracture; and when $\alpha=0$, it is pure DC shear faulting.

When using the principal stress axis coordinate system, Eq. (3) can be written in the following diagonal form:

$\boldsymbol{M}=u\left[\begin{array}{ccc}\lambda \sin \alpha-\mu(1-\sin \alpha) & 0 & 0 \\ 0 & \lambda \sin \alpha & 0 \\ 0 & 0 & \lambda \sin \alpha+\mu(1+\sin \alpha)\end{array}\right]$.

Then, the matrix trace is as follows:

$\operatorname{trace}(\boldsymbol{M})=(3 \lambda+2 \mu) u \sin \alpha$.

Under the constraints that have physical significance, $(\mu>0, \lambda / \mu>-2 / 3)$, the trace of matrix $\boldsymbol{M}$ is only related to the included angle $\alpha$ between the slip vector and the fault plane. Therefore, for an extension-type source, the 

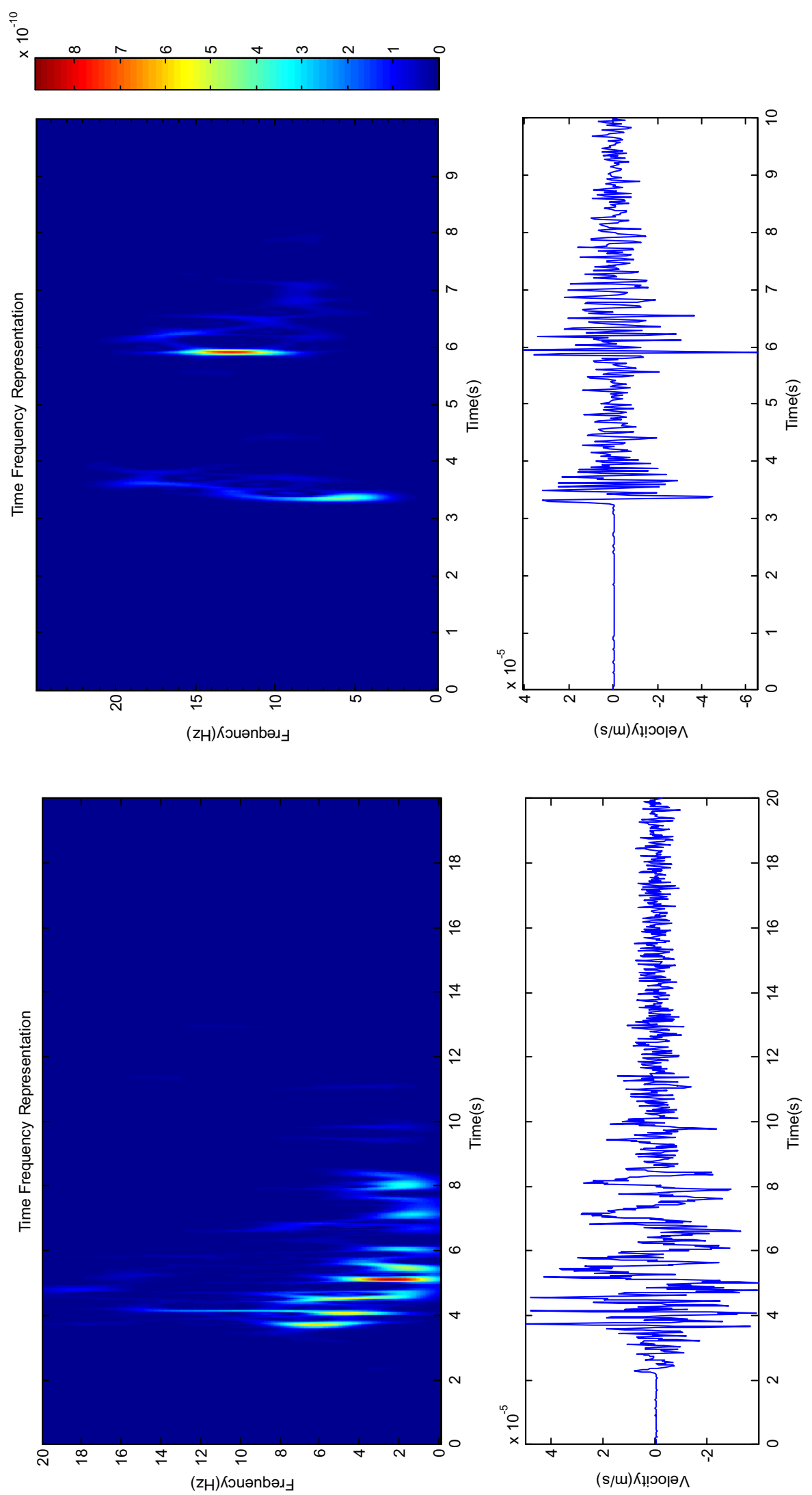

Fig. 4 Energy spectrum of vertical velocity records at BSH station. Left-hand panels for Sept. $12 M_{\mathrm{L}} 2.7$ event; right-hand panels for Nov. 25 $M_{\mathrm{L}} 2.4$ event 
trace of matrix $\boldsymbol{M}$ is positive; otherwise, it is a compression-type source. We designate this by $\lambda / \mu=\kappa$ as the moment tensor can be decomposed into

$\boldsymbol{M}=\boldsymbol{M}^{\mathrm{ISO}}+\boldsymbol{M}^{\mathrm{CLVD}}+\boldsymbol{M}^{\mathrm{DC}}$.

We can obtain the various components in the moment tensor in the following proportions:

$c^{\mathrm{ISO}}=\frac{1}{3} \frac{\operatorname{trace}(\boldsymbol{M})}{\left|M_{|\max |}\right|} 100 \%$,

$c^{\mathrm{CLVD}}=2 \varepsilon\left(100 \%-\left|c^{\mathrm{ISO}}\right|\right)$,

$c^{\mathrm{DC}}=100 \%-\left|c^{\mathrm{ISO}}\right|-\left|c^{\mathrm{CLVD}}\right|$,

where $M_{|\max |}$ is the maximum absolute value of the characteristic value of the moment tensor $\boldsymbol{M}$ and $\varepsilon$ is the DC component corresponding to the CLVD component, defined as

$\varepsilon=-\frac{M_{|\min |}^{*}}{\left|M_{|\max |}^{*}\right|}$,

where $M_{|\min |}^{*}$ and $M_{|\max |}^{*}$ are, respectively, the minimum and maximum absolute values of the characteristic value of the deviatoric moment tensor $\boldsymbol{M}^{*}$.

Based on Eqs. (5), (7), and (8), Vavryčuk (2001) devised the following equation:

$$
\begin{gathered}
\kappa=\frac{2}{3}\left[\frac{\operatorname{trace}(\boldsymbol{M}) / 3}{M_{\max }^{*}+M_{\min }^{*}}-1\right]=\frac{4}{3}\left[\frac{c^{\mathrm{ISO}}}{c^{\mathrm{CLVD}}}-1\right], \\
\alpha=\arcsin \left[3 \frac{M_{\max }^{*}+M_{\min }^{*}}{\left|M_{\max }^{*}\right|+\left|M_{\min }^{*}\right|}\right] .
\end{gathered}
$$

We can infer from the formula that, based on the proportion of different moment tensor components, the specific value of the Lamé coefficient of the fracture fault and the dip of the slip vector of the fault in relation to fault plane can be calculated.

\subsection{Method for moment tensor inversion}

We used ISOLA package to do the waveform moment tensor inversion in time domain (Sokos and Zahradník 2013, 2008). For small earthquakes, the synthetic seismogram can be approximated with a combination of basic seismograms corresponding to six basic types of source mechanism:

$S(t)=\operatorname{sum}\left[a_{i} \times E_{i}(t)\right]$,

where $E_{i}(t), \quad i=1,2, \ldots, 6$, is six basic seismograms; $a_{i}$ is the coefficient to be solved, which is related to the moment tensor, $M_{i j}$, in the following geographical coordinates (north, east, and up are positive):

$$
\begin{aligned}
& M_{x x}=-a_{4}+a_{6} \\
& M_{y y}=-a_{5}+a_{6} \\
& M_{z z}=a_{4}+a_{5}+a_{6} \\
& M_{x y}=M_{y x}=a_{1} \\
& M_{x z}=M_{z x}=a_{2} \\
& M_{y z}=M_{z y}=-a_{3}
\end{aligned}
$$

The use of the least-squares method to solve the inversion problem minimizes the degree of misfit between the observed waveform and the synthetic waveform. The misfit function is defined as follows:

misfit $=\frac{\sum_{i=1}^{n} \frac{\mathrm{obs}_{i}-\mathrm{syn}_{i}}{\max \left(\left|\mathrm{obs}_{\mathrm{i}}\right|,\left|\mathrm{syn}_{\mathrm{i}}\right|\right)}}{n}$,

where $i=1,2, \ldots, n ; n=$ number of stations $\times$ number of vector components $\times$ number of frequency of use.

Green's functions were calculated using Bouchon's discrete wavenumber method (Bouchon 1981) and the original waveform recordings were calibrated experimentally. The appropriate frequency band was selected for band-pass filtering, e.g., $0.10-0.25 \mathrm{~Hz}$ for $M_{\mathrm{L}} 3$ event. $5 \%$ of cosine taper is used for FFT. A grid search method for a preset trial hypocentral location and time displacement was used to determine the optimum result.

\section{Results}

We obtained the source moment tensor solutions of eight events in this earthquake swarm (Tables 1, 2, 3). The $\kappa$ value in Table 2 shows that all the inversion results are in a physically significant range. Figure 5 shows a beach ball representation of the moment tensor solutions.

\subsection{December 20, $2010 M_{\mathrm{L}} 3.4$ event}

As this event was the largest, all the broadband digital seismic stations within $150 \mathrm{~km}$ of the epicenter recorded clear waveform signals. We chose the data from six stations (LQU, WLS, YSH, NLA, XIT, and TIA) with epicentral distances within $100 \mathrm{~km}$ for the moment tensor studies.

The calculated scalar seismic moment for this event was $1.588 \times 10^{14} \mathrm{~N} \mathrm{~m}$, the focal depth was $5 \mathrm{~km}$, and the optimized DC source mechanism solutions were nodal plane $A$ strike $302^{\circ}$, dip $38^{\circ}$, rake $-49^{\circ}$; and nodal plane $B$ strike $75^{\circ}$, dip $61^{\circ}$, rake $-116^{\circ}$; see Fig. 5 for moment tensor solutions.

The correlation coefficient of the optimum synthetic waveform solution was nearly 0.8 , showing a good inversion result. The moment tensor solution results showed that 
Table 1 Moment tensor components of earthquake events in the Boshan swarm

\begin{tabular}{|c|c|c|c|c|c|c|}
\hline \multirow[t]{2}{*}{ Event ID } & \multicolumn{6}{|c|}{ Moment tensor components $\left(10^{10} \mathrm{~N} \mathrm{~m}\right)$ in geographical coordinate system (NE down) } \\
\hline & $M_{\mathrm{rr}}$ & $M_{\mathrm{tt}}$ & $M_{\mathrm{pp}}$ & $M_{\mathrm{rt}}$ & $M_{\mathrm{rp}}$ & $M_{\mathrm{tp}}$ \\
\hline 201009121138 & -158.17 & 183.03 & 171.84 & -45.57 & 68.27 & -108.23 \\
\hline 201011241356 & 790.90 & -529.93 & 152.01 & 196.71 & -45.95 & 30.67 \\
\hline 201011252055 & -36.164 & 3.398 & 32.767 & -100.034 & -1.624 & 53.241 \\
\hline 201011271942 & 58.88 & 218.50 & 60.14 & -217.34 & 69.71 & -89.90 \\
\hline 201011291539 & -50.78 & 223.94 & 102.24 & 34.03 & -16.90 & 76.76 \\
\hline 201012020553 & 2.99 & 3.08 & 1.688 & -2.26 & 4.18 & 0.60 \\
\hline 201012020624 & 6.91 & 13.80 & 1.98 & -4.01 & 10.29 & 1.22 \\
\hline 201012201555 & 368.5 & 2047.00 & 546.60 & -416.20 & 104.75 & 156.23 \\
\hline
\end{tabular}

Table 2 Source parameters for events in the Boshan swarm

\begin{tabular}{lcllcccc}
\hline Event ID & $\begin{array}{l}\text { Seismic moment }\left(10^{12}\right. \\
\text { N m })\end{array}$ & $\begin{array}{l}\text { Moment magnitude } \\
M_{\mathrm{W}}\end{array}$ & $\begin{array}{l}\text { Average correlation } \\
\text { coefficient }\end{array}$ & $\begin{array}{l}\text { ISO } \\
(\%)\end{array}$ & $\begin{array}{l}\text { CLVD } \\
(\%)\end{array}$ & $\begin{array}{l}\text { DC } \\
(\%)\end{array}$ & $\begin{array}{l}\kappa \\
201009121138\end{array}$ \\
2.499 & 2.2 & 0.454 & 21.9 & 3.3 & 75.0 & 8.18 \\
201011241356 & 7.117 & 2.6 & 0.611 & 16.7 & 3.3 & 80.0 & 6.08 \\
201011252055 & 1.185 & 2.0 & 0.503 & 0 & 24.5 & 75.5 & 0 \\
201011271942 & 2.960 & 2.3 & 0.373 & 27.6 & 43.8 & 28.6 & 0.17 \\
201011291539 & 1.981 & 2.2 & 0.339 & 34.7 & 15.8 & 49.4 & 2.26 \\
201012020553 & 0.059 & 1.1 & 0.532 & 36.6 & 16.7 & 46.7 & 2.25 \\
201012020624 & 0.156 & 1.4 & 0.551 & 44.3 & 37.1 & 18.6 & 0.93 \\
201012201555 & 158.78 & 3.4 & 0.667 & 45.8 & 36.5 & 17.7 & 1.01 \\
\hline
\end{tabular}

Table 3 Parameters of fault planes of events of Boshan swarm

\begin{tabular}{|c|c|c|c|c|c|c|}
\hline \multirow[t]{2}{*}{ Event ID } & \multicolumn{3}{|c|}{ Nodal plane $A$} & \multicolumn{3}{|c|}{ Nodal plane $B$} \\
\hline & Strike $\left(^{\circ}\right)$ & $\operatorname{Dip}\left(^{\circ}\right)$ & Rake $\left(^{\circ}\right)$ & Strike $\left(^{\circ}\right)$ & $\operatorname{Dip}\left(^{\circ}\right)$ & Rake $\left(^{\circ}\right)$ \\
\hline 201009121138 & 309 & 35 & -97 & 138 & 55 & -85 \\
\hline 201011241356 & 95 & 53 & 93 & 269 & 36 & 84 \\
\hline 201011252055 & 185 & 30 & -161 & 78 & 80 & -61 \\
\hline 201011271942 & 321 & 14 & -55 & 105 & 79 & -98 \\
\hline 201011291539 & 7 & 28 & -110 & 210 & 63 & -79 \\
\hline 201012020553 & 186 & 5 & 125 & 331 & 86 & 87 \\
\hline 201012020624 & 232 & 25 & 177 & 325 & 89 & 65 \\
\hline 201012201555 & 302 & 38 & -49 & 75 & 61 & -116 \\
\hline
\end{tabular}

To explain the authenticity of the non-DC components in the moment tensor solutions, inversion was carried out again with the source mechanisms constrained to pure DC solutions; the solutions at different depths are shown in Fig. 8. This figure shows that the degree of waveform correlation of the optimum pure DC solutions at various depths is significantly lower than the moment tensor solutions, explaining the authenticity and reliability of the non-DC components in the moment tensor solutions.

Table 2 shows that, except for the three initial events, the proportion of the DC components in the events was very small $(<60 \%)$. Trifu and Shumila (2002) found that large non-DC components appeared in some mine 
(a)

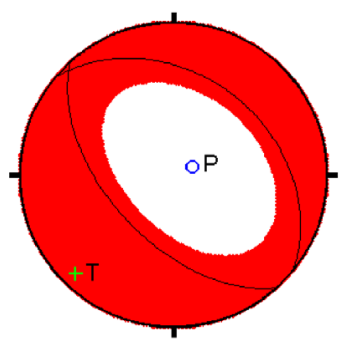

(b)

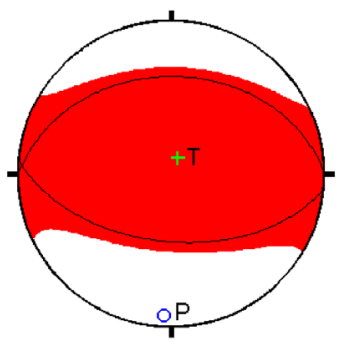

(c)

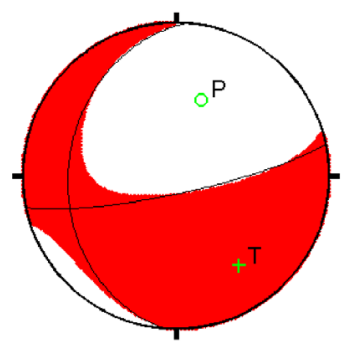

(d)

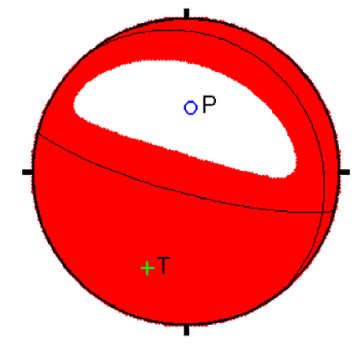

(h)

(g)
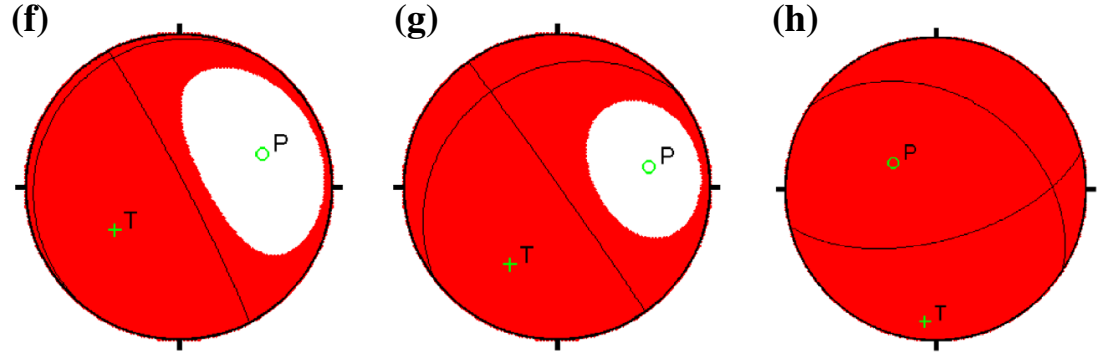

Fig. 5 Source mechanisms of eight events studied in this work. a 2009121138, b 2011241356, c 2011252055, d 2011271942, e 2011291539, f 2012020553, g 2012020624, h 2012201555

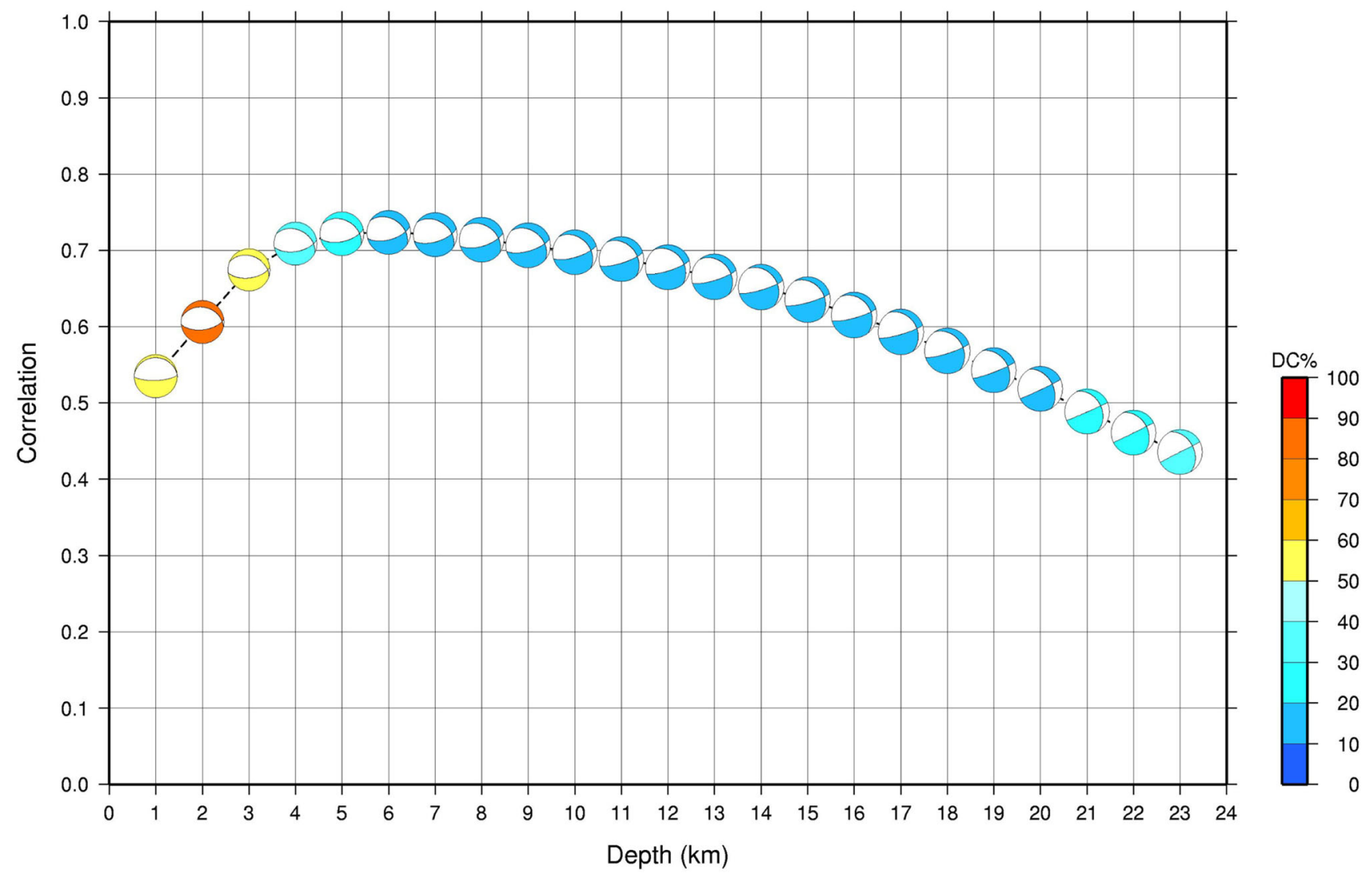

Fig. 6 Waveform misfit function for optimized source mechanisms at different depths 

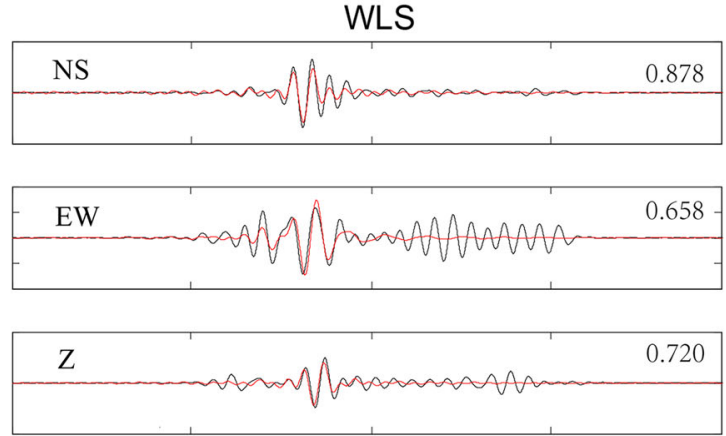

YSH

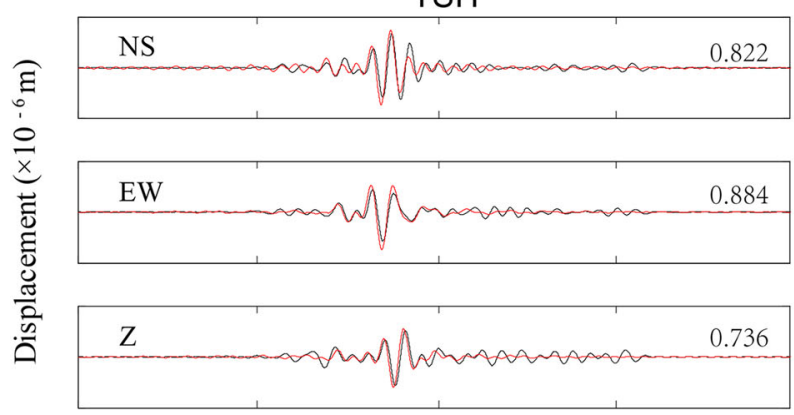

LQU

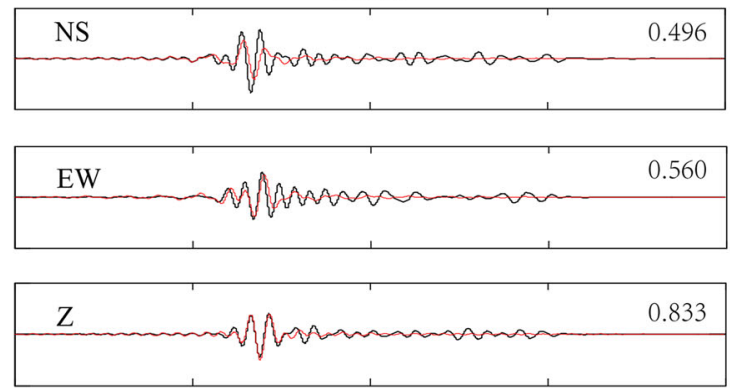

Time (s)
XIT
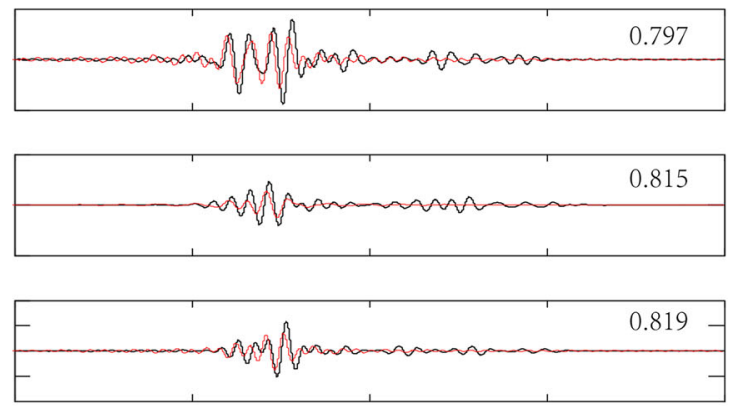

TIA
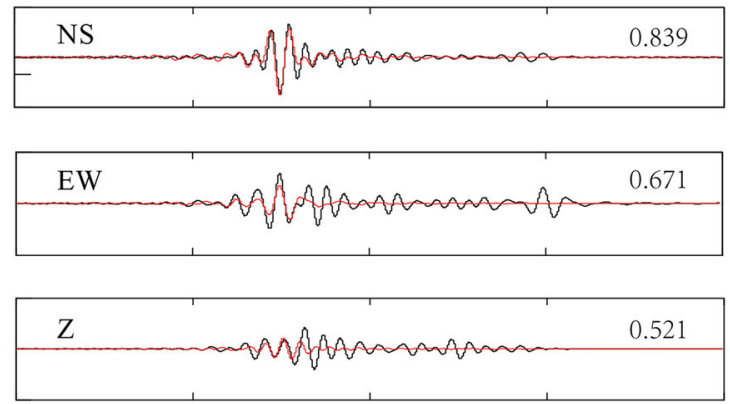

Time (s)

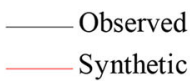

Fig. 7 Fitness of synthetic waveforms and filtered observations, numbers at right-top of each component are correlation coefficient between synthetics and observations

earthquake events in which the shear faulting components were $15 \%-20 \%$; their analysis showed that the moment tensor results were reliable. Dahm et al. (2000) studied the accuracy of the seismic source mechanism by comparing the absolute and relative moment tensor solutions; they estimated the error caused by the medium model and inaccurate amplitude data. Dahm et al. (2000) suggested that the significantly high level of similar non-DC components was not caused by inaccurate moment tensor inversion and that a large proportion of these non-DC components reflected the special properties of the seismic sources or media.
Miller et al. (1998) used statistics to show that many mine earthquakes contain non-DC mechanisms and that the first motion is inconsistent with a normal quadrantal distribution. Stickney and Sprenke (1993) studied 21 mine earthquakes (rock burst) in the Coeur d'Alene mining area, Idaho, USA, and found that $90 \%$ of the P-wave first motions observed were downward and that the first motions of 11 of the 21 events were negative. The first motion polarities from 25 stations for the Dec 20, $2010 M_{\mathrm{L}}=3.4$ event were obtained from the waveform data recorded by the Shandong Seismic Networks. In contrast to ordinary mine earthquakes, most of the first motions were upward 


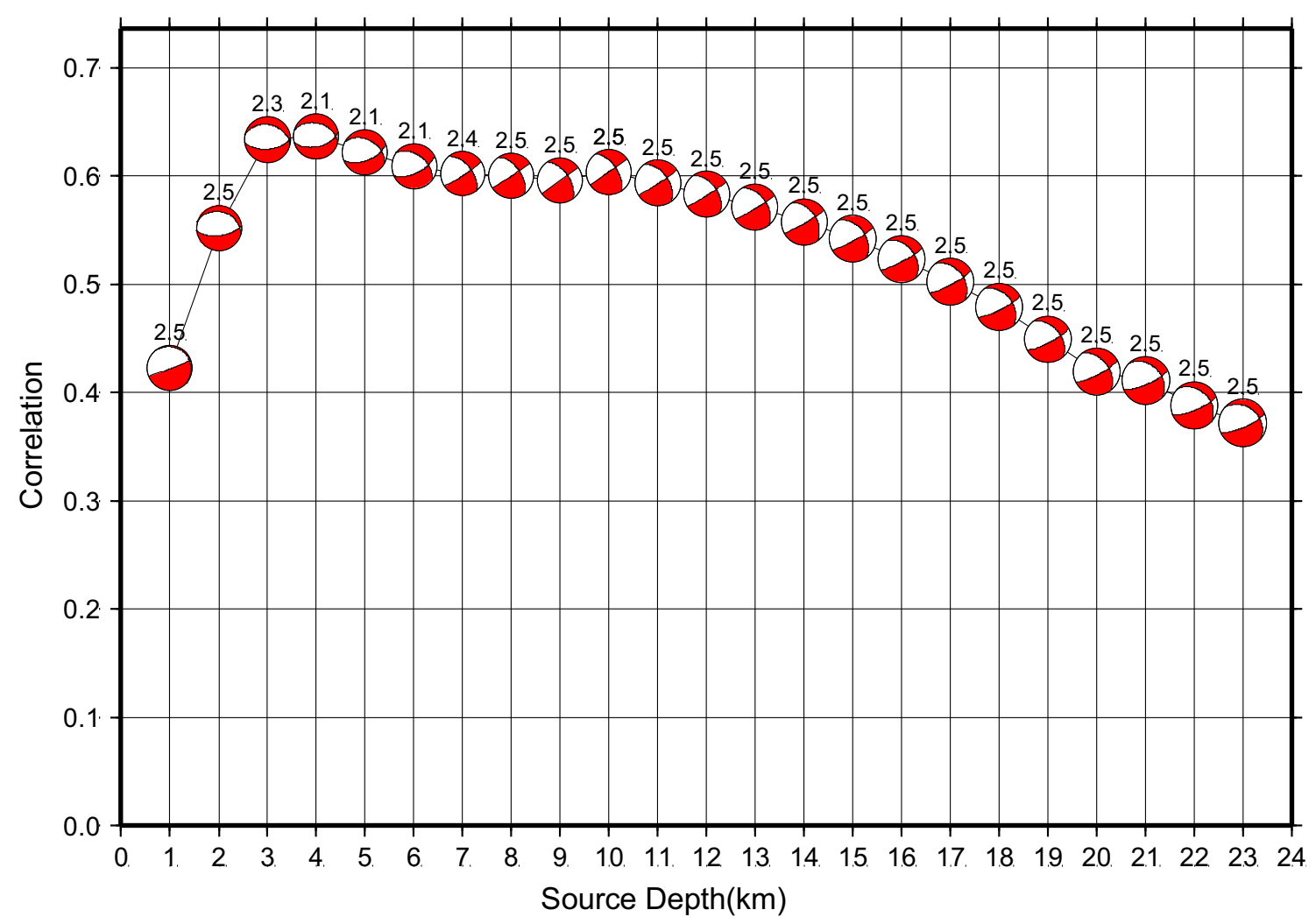

Fig. 8 Waveform misfit function for optimized DC source mechanisms at different depths. The values above the beach balls give the time shift

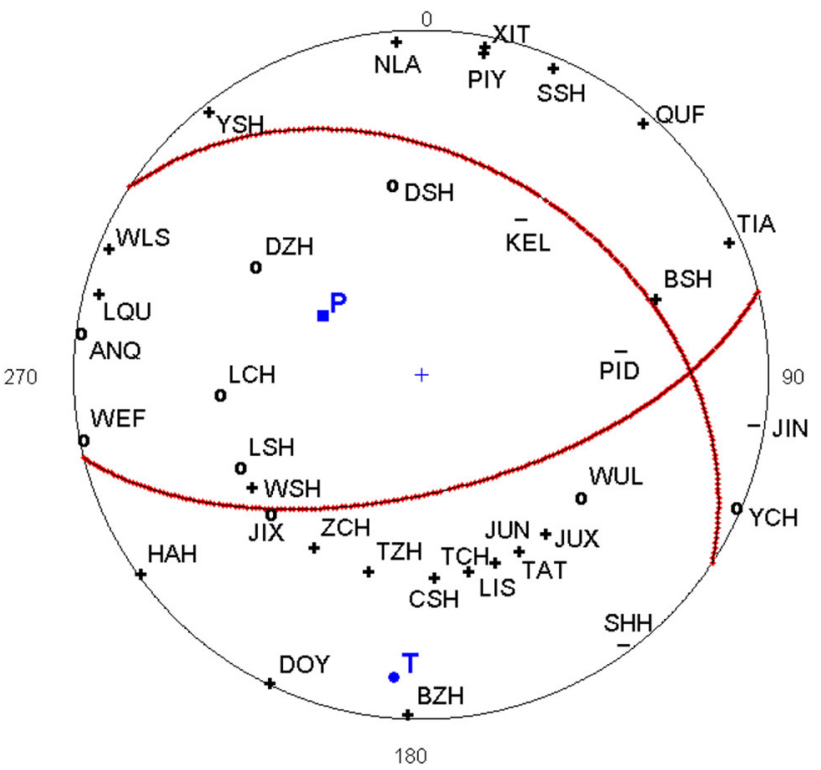

Fig. 9 Source mechanisms and first motion polarities of December 20 event with $M_{\mathrm{L}} 3.4$; Symbols 'o' on the beach ball denote that the first motions are ambiguous at these stations

and even the downward first motions observed by three stations were not obvious; the possibility of misreading cannot be ruled out. Figure 9 shows the correspondence between the source mechanism solutions obtained by MT inversion and the first motion polarities; the results include nine stations with an epicentral distance within $200 \mathrm{~km}$, but which could not determine a clear first motion. Figure 9 shows that because the volume components in this seismic source were large, in the first motion expansion zone in which the first motion should originally be downward, the first motions observed by many stations were blurred. Many positive first motion polarities were observed and this further supports the reliability of solutions from moment tensor inversion.

\section{Discussion}

For non-DC components in seismic moment tensor solutions, some seismic moment tensor analysis has shown (Miller et al. 1998; Trifu and Shumila 2002; Horálek et al. 2010) that, under certain circumstances (e.g., mine earthquakes due to reservoir filling, water injection in oil production, volcanic activity and geothermal eruption, landslides, collapses, and subsidence), the non-DC components (the CLVD and ISO components) may form a large proportion of the total. Julian et al. (1998) summarized the moment tensor expansion of the equilibrating 
force system and systematically analyzed the possible physical processes of non-DC earthquakes. They gave the theoretically reasonable explanations that the non-DC rupture process may have its roots in the shear faulting and extension fracture of complex faults, or in shear faulting or polymorphic phase transition in anisotropic media.

The results for the solution of typical mine earthquake focal mechanisms induced by mining operations often show a large implosion component and, as the goafs collapsed, non-DC components in moment tensor solutions. The ISO and CLVD components are negative, indicating the existence of a large amount of uniaxial compression accompanying volume reduction (McGarr 1992a, b; Julià et al. 2009). The computation of this Boshan earthquake swarm events showed that, at the beginning of swarm activity, the DC components formed a large proportion of the source mechanisms $(>75 \%)$, whereas the non-DC components may be attributed, to some extent, to inversion error due to constraints in the observed data. However, the moment tensor in the later events showed very large nonDC components and the ISO and CLVD components were both positive, indicating that the seismic sources were tensile cracks.

\subsection{Stress state and orientation of $P, T$ axes}

Previous studies of the source mechanisms of typical mine earthquake events have shown (McGarr 1992a, b; Julià et al. 2009) that the maximum stress in mine earthquake sources is compressive stress in a nearly vertical direction, accompanied by a reduction in volume and normal faulting; this is consistent with the closure of goafs as a result of gravity.

Figure 10 shows the orientation of the $P, T$ axes in eight of the mine earthquake events studied in this work. Except for one tectonic earthquake event (201011241356), the $P$ axis in the other seven events is orientated in a nearly vertical direction and the DC components show normal faulting. However, in contrast with the findings of Julià et al. (2009), the maximum stress in these events was tensile stress. The $T$ axis was orientated to the southwest in the projection direction of the focal sphere, indicating that the source rupture in these mine earthquake events was largely caused by the action of tensile stress in the southeast in a nearly horizontal direction. The projection of the slip vectors on the focal sphere shows that, apart from the event $16 \mathrm{~km}$ south of the earthquake swarm on November 25,2010 , the projection direction of the seismic source slip vectors of the earthquake swarm was relatively stable.

Feignier and Young (1992) created many non-DC mechanism earthquakes by explosions in a 3.5-m-wide mine tunnel cut into complete granite in the Manitoba URL Laboratory, Canada. They calculated the moment tensors of 33 recorded microquakes with moment magnitudes ranging from -2 to -4 and found that tensile events mainly occurred around the caved areas at the top of the mine tunnels and that the implosion events usually occurred in front of active surfaces. Their computation showed that the maximum principal stress in the area was characterized by a positive tensile stress and that the tectonic stress background could explain the existence of a tensile source.

In Boshan District, Zibo City is considered to be a seismic window for Shandong because there are frequent small swarms of earthquakes and microquakes. This area often had an obvious concentrated activity of small earthquakes before the occurrence of moderately strong earthquakes in the zone (within about $500 \mathrm{~km}$ ). ( $\mathrm{Su}$ 1997) Boshan District lies around the top of the arc of a horseshoe-shaped structure in west Shandong where stress tends

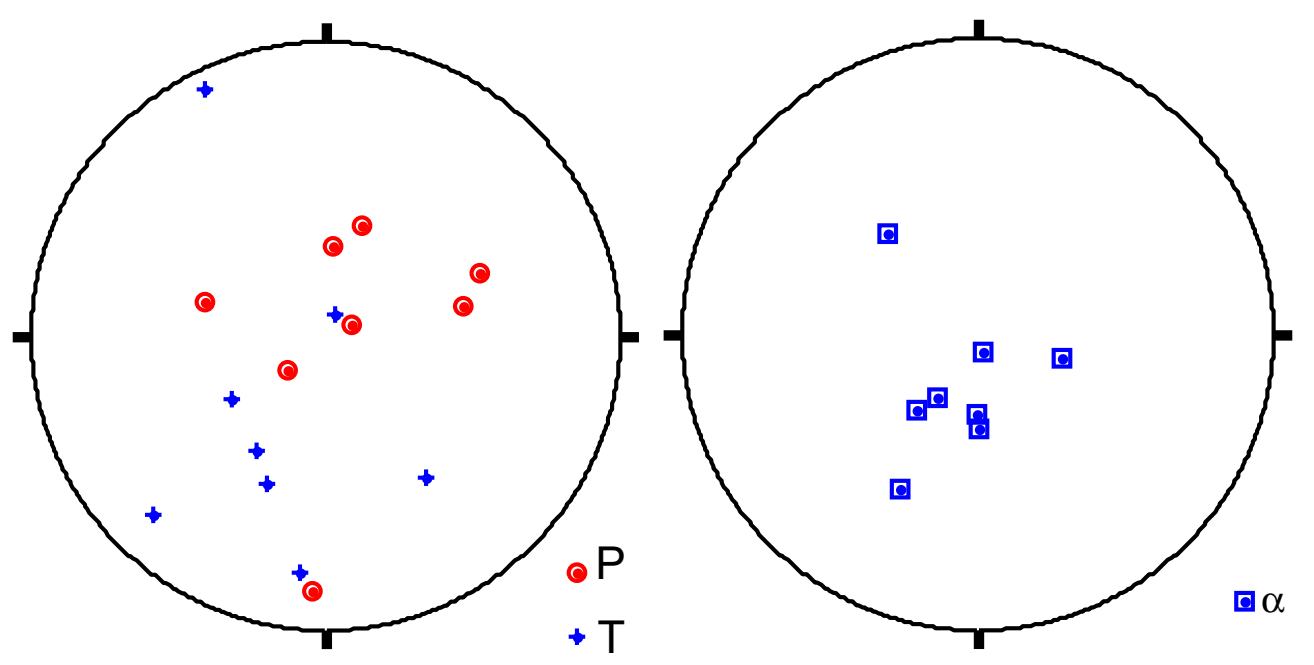

Fig. 10 Positions of $P, T$ axes (left) and slip vectors ( $\alpha$ in right panel) on equal area lower focal hemisphere projections 
to concentrate. Faults are developing in this structure, mostly in the form of high-level normal faults; reverse faults are rare. The data show that (Jiao et al. 1990) the epicenters are mainly in the Zibo syncline; this strikes $c$. $40^{\circ}-50^{\circ} \mathrm{NE}$ and trends to NW at an angle of $15^{\circ}-18^{\circ}$. The direction of tensile stress caused by pure rock gravity therefore does not fit with the computation. The epicenter of this earthquake swarm was mainly the Wangmu Mountain fault in a northeasterly direction. According to Shi et al. (2009), the Wangmu Mountain fault trends west with a dip of about $75^{\circ}$ and the activity is mainly in the form of normal faults. Although these fracture properties are close to our moment tensor for tensile cracking, the strike of this fault is inconsistent with the inversion result. The Yuwang Mountain fault lies $6 \mathrm{~km}$ to the west of this earthquake swarm and strikes $2^{\circ}-10^{\circ} \mathrm{NE}$, trending approximately east with a dip of $60^{\circ}-80^{\circ}$, and is mainly characterized by a tensile structure. About $5 \mathrm{~km}$ to the south of the epicenter, the Shentou-Xihe fault strikes $40^{\circ}$ $60^{\circ} \mathrm{NE}$, trending to the SE with a dip of $60^{\circ}-70^{\circ}$. Therefore, within the small structural unit enclosed by the above three areas of extension tectonics, there is also tension in the main stress direction. The small earthquake moment tensor we obtained through inversion is consistent with this analytical result.

According to data from the Mining Bureau of Zibo (Jiao et al. 1990), there are two groups of secondary faults in research area besides large fault shown in Fig. 2. The 1st group spread approximately in EW direction; the 2nd group arranged in NW direction with normal faulting. As no more accurate data about these secondary faults are available, it is impossible to judge which group of faults these swarm events are related to. However, we are certain that the swarm is caused by fracture tectonic activity related to the Wangmu Mountain fault under the conditions of stress adjustment in this small area of Boshan District.

\subsection{Analysis of causes for Boshan earthquake swarm activities}

There are many possible sources for non-DC source mechanisms. If multiple shear faulting occurs in conterminous, but different, fault planes, or the shear faulting of non-planar faults is mistakenly considered as an event, then the real DC tensor and moment tensor of the combined events are usually non-DC tensors (Frohlich 1994). In this case, shear faulting may generate a non-DC mechanism; however, there is no isotropic volume component. As the trace of the combined moment tensor is equal to the sum of the traces of its components, the combination of DC tensors cannot generate non-zero ISO components (Horálek et al. 2010).

The heterogeneity or anisotropism of the underground media may also result in the appearance of non-DC components in the moment tensor solutions of shear faulting. The experiments of Kawasaki and Tanimoto (1981) and the studies of Vavryčuk (2002) have shown that the anisotropism and heterogeneity of the underground media are not the main causes of higher non-DC mechanisms. Considering that the data from field mobile stations were used in our studies of the earthquakes that occurred in the period December 2-5, 2010 within a small range with a radius of $<10 \mathrm{~km}$, the properties of the underground media can be assumed to be uniform and the influence of lateral heterogeneity is negligible.

Theoretical and experimental studies on the source causes of tensile earthquakes have been reported previously (Walter and Brune 1993; Scholz 1990). Studies have shown that tensile earthquakes usually occur in areas with large amounts of underground fluids, such as in a geothermal field or near volcanoes (Miller et al. 1998; Baisch et al. 2009). Julian et al. (1998) proposed that highpressure underground fluids are the primary cause of tensile cracking because the existence of fluid pressure may offset rock stresses in the Earth's interior. Fluids under high pressure may rapidly fill the rupture zones when the rocks burst, giving rise to large tensile components (Fig. 11).

Walter et al. (2009) studied the source mechanisms in icequake events caused by the opening of crevasses on the surface layer of the Gornergletscher glacier, Switzerland, using the full waveform inversion method. The moment tensor results showed extensional fractures, indicating the reliability of moment tensor inversion. Walter et al. (2010) showed that the involvement of high-pressure liquids in the rupture process may lead to tensile cracking by studying the moment tensor solutions in icequake events that occurred at the base of glaciers.

In Boshan District, Zibo City has been long known as the Second Spring City of Shandong because there are four groups of springs (Shentou, Qiugu, Zhulong, and Liangzhuang) and more than 40 recorded springs. In addition, a number of geothermal areas and abnormalities in

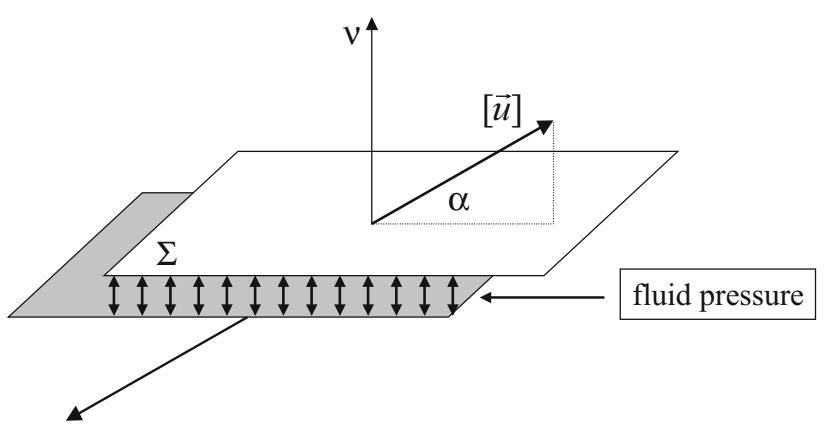

Fig. 11 Model for the tensile source. $\sum$ is the fault plane, $v$ is the normal to the fault, $[\vec{u}]$ is the slip vector, and $\alpha$ is the inclination of the slip vector from the fault plane 
hydrochemistry exist in this area (Yang et al. 2005), which matches the observations in earlier studies that tensile earthquakes with non-DC mechanisms mainly occur in areas where there are large underground geothermal fluids or volcanoes. Therefore, the large non-DC components in the moment tensor solutions of the Boshan swarm may be caused by the involvement of underground fluids in the rupture process in the source area.

Moment tensor analysis showed that (except for the three events that occurred on September 12, November 24, and November 25,2010$)$ the mechanism in the early stages of the swarm was primarily tensile cracking. As massive underground fluids are present in this area, the main cause of the earthquakes was shear faulting at the beginning of swarm activity. After fracturing, underground fluids with a high pore pressure filled the burst area, reducing the friction stress and making a second rupture easier, which resulted in a continuously active earthquake swarm. The high pore pressure also gives rise to the source mechanism of tensile cracking. The results of rock crushing tests support tensile cracking (Byerlee 1990). Špičák and coworkers (2000) and Horálek et al. (2002) studied the West Bohemian region of the Czech Republic and they proposed that high fluid pressures may be a key factor in the frequent swarm activities in this region. This feature is similar to that of the Boshan seismic window. Therefore, we conclude that underground fluids with high pore pressures were involved in the rupture of the hypocentral region and played an important role in the activity of the Boshan earthquake swarm.

It is usually thought that full moment tensor solution retrieved by inverting seismograms may include errors due to incomplete knowledge of the structure along the propagation path. Studies in gold mine in South Africa shows that the full MT solutions inverted from close stations within a few kilometers to the source are believable, even in homogeneous model (Š́lený and Milev 2006). In our study, the farthest temporary station to the swarm is no more than $10 \mathrm{~km}$. Despite a few local stations, the final result should still reliable.

\section{Conclusions}

Using data from the Shandong seismic station networks and waveforms recorded by the temporary station network, we determined the source mechanisms of eight events in a mine earthquake swarm in November and December, 2010 in Boshan District using directional instrumentation and the time domain moment tensor inversion method. We also determined the source mechanism of an earthquake of $M_{\mathrm{L}}$ 2.7 that occurred on September 12, 2010. The following conclusions were drawn.
(1) At the beginning of the swarm activities, the DC components formed a large proportion of the source mechanisms, which may be primarily attributable to shear faulting under tectonic stresses. However, the moment tensors in the following events showed very large non-DC components and the ISO and CLVD components were both positive, indicating that the seismic source was tensile cracking.

(2) The source mechanisms of the swarm events showed that-except for the earthquake event $16 \mathrm{~km}$ to the south on November 24, 2010, which showed reverse faulting - the DC components of the events showed normal faulting. The $P$ axis was almost vertical and the maximum stress was tensile; the projection direction of the source slip vector of the swarm events was relatively reliable.

(3) We analyzed the epicentral tectonic features and suggest that this swarm event was caused by fracture tectonic activity related to the Wangmu Mountain fault undergoing stress adjustment in the small area of Boshan District.

Based on analyses of the reliability of the moment tensor solutions, we proposed that underground fluids with high pore pressures were involved in the rupture process in the source area and played an important role in these Boshan swarm activities.

The results obtained by this study, constrained by the original data and velocity model, showed that the average waveform correlation coefficient of an individual event (e.g., 11291539) was not high; however, the results are still acceptable for microquakes of $M_{\mathrm{L}} 2$ (Fig. 1).

Although these findings showed that the source type at the beginning of the Boshan earthquake swarm activities was mainly fault rupture under tectonic stress, these activities occurred in a mining area where coal goafs have altered the stress distribution inside the underground formations. However, we can make no clear judgment about whether mining activities have caused these swarms. The moment tensor results for this swarm show that the source activities can be divided into two stages. Rupture in the earlier stage may have an influence on the activity in the next stage, although the physical mechanism of their interactions still unclear and requires further study.

Acknowledgments We thank the Earthquake Networks Center of Shandong Province for their hard work and the reviewers of this paper for their valuable comments. This study was partly supported by the program of Science for Earthquake Resilience (XH15026) provided by China Earthquake Administration, and the Science and Technology Development Plan Project of Shandong Province, China (GRANT-2014GSF120007).

Open Access This article is distributed under the terms of the Creative Commons Attribution 4.0 International License (http:// 
creativecommons.org/licenses/by/4.0/), which permits unrestricted use, distribution, and reproduction in any medium, provided you give appropriate credit to the original author(s) and the source, provide a link to the Creative Commons license, and indicate if changes were made.

\section{References}

Aki K, Richards PG (1980) Quantitative Seismology: Theory and Methods. Translated into Chinese by Li QZ, Zou QJ, et al. W. H. Freeman, New York, pp 55-60 (in Chinese)

Baisch S, Vörös R, Weidler R, Wyborn D (2009) Investigation of fault mechanisms during geothermal reservoir stimulation experiments in the Cooper Basin, Australia. Bull Seismol Soc Am 99(1):148-158

Bouchon M (1981) A simple method to calculate Green's functions for elastic layered media. Bull Seismol Soc Am 71(4):959-971

Byerlee J (1990) Friction, over pressure and fault normal compression. Geophys Res Lett 17(12):2109-2112

Chen JH, Gan JS, Wu HB, Zhang LF, Ding YW, Wei GC, Shen XL (2009) Analysis of micro-earthquake swarms in Luoquanhuang area of Zigui County. J Geodesy Geodyn 29(6):45-48 (in Chinese with English abstract)

Dahm T, Horálek J, Š́lený J (2000) Comparison of absolute and relative moment tensor solutions for the January 1997 West Bohemia earthquake swarm. Stud Geophys Geod 44(2):233-250

Feignier B, Young RP (1992) Moment tensor inversion of induced micro-seismic events: evidence of non-shear failures in the $4<M<-2$ moment magnitude range. Geophys Res Lett 19(14): 1503-1506

Fletcher JB, McGarr A (2005) Moment tensor inversion of ground motion from mining-induced earthquakes, Trail Mountain, Utah. Bull Seismol Soc Am 95(1):48-57

Frohlich C (1994) Earthquakes with non-double-couple mechanisms. Science 264(5160):804-809

Gibowicz SJ (1995) Scaling relations for seismic events induced by mining. Pure appl Geophys 144(2):191-209

Gibowicz SJ, Kijko A (1998) In: An introduction to mining seismology. Translated into Chinese by Xiu JG, Xu P, Yang XP. Seismological Press, Beijing pp 232-238

He XS, Li SY, Shen P, Feng QX (2006) A wavelet packet approach to wave classification of earthquakes and mining shocks. Earthq Res China 22(4):425-434 (in Chinese with English abstract)

He X, Li S, Pan K, Zhang TZ, Wang LY, Xu ZH, Jiang XQ, Song XY, Lu QH, He SY (2007) Mining seismicity, gas outburst and the significance of their relationship in the study of physics of earthquake sources. Acta Seismol Sinca 29(3):314-327 (in Chinese with English abstract)

Horálek J, Š́lený J, Fischer T (2002) Moment tensors of the January 1997 earthquake swarm in NW Bohemia (Czech Republic): double-couple vs. non-double-couple events. Tectonophysics 356(1-3):65-85

Horálek J, Jechumtálová Z, Dorbath L, Šílený J (2010) Source mechanisms of micro-earthquakes induced in a fluid injection experiment at the HDR site Soultz-sous-Forêts (Alsace) in 2003 and their temporal and spatial variations. Geophys $\mathrm{J}$ Int 181(3):1547-1565

Jiang WW, Hao TY, Jiao CM, Song HB (2000) The characters of gravity and magnetic fields and crustal structure from Qingzhou to Muping, Shandong Province. Prog Geophys 15(4):18-26 (in Chinese with English abstract)

Jiao RF, Yang CY, Liu BL et al (1990) Annals of Boshan. People's Press of Shandong Province, Jinan, pp 1-682 (in Chinese)
Julià J, Nyblade AA, Durrheim R, Linzer L, Gök R, Dirks P, Walter W (2009) Source mechanisms of mine-related seismicity, Savuka Mine, South Africa. Bull Seismol Soc Am 99(5):2801-2814

Julian BR, Miller AD, Foulger GR (1998) Non-double-couple earthquakes 1: theory. Rev Geophys 36(4):525-549

Kawasaki I, Tanimoto T (1981) Radiation patterns of body waves due to the seismic dislocation occurring in an anisotropic source medium. Bull Seismol Soc Am 71(1):37-50

Li T, Cai M, Zuo Y, Liu YQ (2005) Features of focal mechanisms of mining-induced earthquakes: a case study of the Fushun Laohutai coal mine, Liaoning Province. Geol Bull China 24(2):136-144 (in Chinese with English abstract)

Lin HC, Wang BP, Liu HR, Jiang JK (1990) Comparative study of tectonic and collapse earthquakes. Acta Seismol Sinca 12(4):448-455 (in Chinese with English abstract)

Liu XQ, Du YH, Xu B, Li H, Shen P, Zhang P (2005) The mode identification method and its application to regional mine and natural earthquakes. Earthq Res China 21(1):50-60 (in Chinese with English abstract)

McGarr A (1992a) An implosive component in the seismic moment tensor of a mining-induced tremor. Geophys Res Lett 19(15):1579-1582

McGarr A (1992b) Moment tensors of ten Witwatersrand mine tremors. Pure appl Geophys 139(3-4):781-800

McGarr A (1994) Earthquake source mechanics and fracture mechanics: theory and observation: some comparisons between mining-induced and laboratory earthquakes. Pure appl Geophys 142(3-4):467-489

McGarr A, Boettcher M, Fletcher JB, Sell R, Johnston MJS, Durrheim R, Spottiswoode S, Milev A (2009) Broadband records of earthquakes in deep gold mines and a comparison with results from SAFOD, California. Bull Seismol Soc Am 99(5):28152824

Miller A, Foulger G, Julian B (1998) Non-double-couple earthquakes 2: observations. Rev Geophys 36(4):551-568

Oye V, Bungum H, Roth M (2005) Source parameters and scaling relations for mining-related seismicity within the Pyhäsalmi Ore Mine, Finland. Bull Seismol Soc Am 95(3):1011-1026

Phillips WS, Pearson DC, Yang X, Stump BW (1999) Aftershocks of an explosively induced mine collapse at White Pine, Michigan. Bull Seismol Soc Am 89(6):1575-1590

Scholz CH (1990) The mechanics of earthquakes and faulting. Cambridge University Press, New York, pp 66-100

Shen P, Yang XH, Mao ZY, Gao MQ, Wu SY, Ye TL (2006) Research on nucleation of earthquake in $\mathrm{km}$-size experiment. Prog Geophys 21(3):717-721 (in Chinese with English abstract)

Shi QM, Wang HS, Wang T (2009) Geophysical exploration of Wangmushan fault and the activities of the times. Eng Des Ground 11:96-98 (in Chinese with English abstract)

Š́lený J, Milev A (2006) Seismic moment tensor resolution on a local scale: simulated rockburst and mine-induced seismic events in the Kopanang gold mine, South Africa. Pure appl Geophys 163(8):1495-1513

Sokos E, Zahradník J (2008) ISOLA a Fortran code and a Matlab GUI to perform multiple-point source inversion of seismic data. Comput Geosci 34:967-977

Sokos E, Zahradník J (2013) Evaluating centroid moment tensor uncertainty in new version of ISOLA software. Seismol Res Lett 84:656-665

Špičák A (2000) Earthquake swarm and accompanying phenomena in intraplate regions: a review. Stud Geophys Geod 44(2):89-106

Stec K (2007) Characteristics of seismic activity of the Upper Silesian Coal Basin in Poland. Geophys J Int 168(2):757-768 
Stickney M, Sprenke K (1993) Seismic events with implosional focal mechanisms in the Coeur d'Alene Mining District, Northern Idaho. J Geophys Res 98(B4):6523-6528

Su LS (1997) A study of prediction effectiveness of Boshan seismic situation window. North China Earthq Sci 15(3):40-44 (in Chinese with English abstract)

Trifu C, Shumila V (2002) Reliability of seismic moment tensor inversions for induced micro seismicity at Kidd Mine, Ontario. Pure appl Geophys 159(1-3):145-164

Vavryčuk V (2001) Inversion for parameters of tensile earthquakes. J Geophys Res 106(B8):16339-16358

Vavryčuk V (2002) Non-double-couple earthquake of 1997 January in West Bohemia, Czech Republic: evidence of tensile faulting. Geophys J Int 149(2):364-373

Walter WR, Brune JN (1993) Spectra of seismic radiation from tensile crack. J Geophys Res 98(B3):4449-4459

Walter F, Clinton JF, Deichmann N, Dreger DS, Minson SE, Funk M (2009) Moment tensor inversions of icequakes on Gornergletscher, Switzerland. Bull Seismol Soc Am 99(2A):852-870
Walter F, Dreger DS, Clinton JF, Deichmann N, Funk M (2010) Evidence for near-horizontal tensile faulting at the base of Gornergletscher, a Swiss Alpine glacier. Bull Seismol Soc Am 100(2):458-472

Yang X, Stump BW, Phillips WS (1998) Source mechanism of an explosively induced mine collapse. Bull Seismol Soc Am 88(3):843-854

Yang S, Zhang HD, Li WZ, Wu L (2005) Genesis of geothermal anomaly in Southern Zhangdian District of Zibo City. Hydrogeol Eng Geol 32(3):59-62 (in Chinese with English abstract)

Zhang SQ, Zhang C, Xiu JG, Guan J, Liu YC, Zhang ZP, Dong JP, Xiao LX, Chen G, Li WP (1993) Review of mines seismicity. Progress in Geophysics 8(3):69-85 (in Chinese with English abstract)

Zhang LF, Liao WL, Zeng XS, Zhong YY (2009) Analysis of timefrequency characteristics of wave spectrum between tectonic earthquake and mine earthquake. Seismol Geol 31(4):699-706 (in Chinese with English abstract) 